\title{
PENGARUH BRAND EXPERIENCE, BRAND TRUST, CUSTOMER SATISFACTION TERHADAP BRAND LOYALTY PRODUK CIMORY
}

\author{
Maria Yoana \\ Program Studi Magister Manajemen Universitas Tarumanagara \\ maria.baggins@yahoo.com \\ Miharni Tjokrosaputro \\ Program Studi Magister Manajemen Universitas Tarumanagara
}

\begin{abstract}
Over time, the company experienced intense business competition between companies. This competition is also experienced by consumer goods companies namely food and beverage companies, including fermented milk companies or yogurt. The company strives to carry out a marketing strategy to be able to deal with its competitors. Therefore, company management must have a specific strategy for making products, maintaining products and generating customer satisfaction, which will thus lead to high loyalty from consumers to the products released by the company. One company that is experiencing business competition is Cimory. Cimory produces yogurt with a variety of flavors, and its competitors are Yakult who have been in Indonesia for a long time. This study will discuss how the influence of brand experience, brand trust, Cimory's customer satisfaction on brand loyalty in the eyes of consumers.
\end{abstract}

Abstrak : Seiring perkembangan waktu, perusahaan mengalami persaingan bisnis yang ketat antara perusahaan. Persaingan ini juga di alami oleh perusahaan consumer goods yakni perusahaan makanan dan minuman, termasuk diantaranya perusahaan susu fermentasi atau yoghurt. Perusahaan berupaya melakukan strategi pemasaran untuk mampu menghadapi perusahaan pesaingnya. Oleh karena itu, manajemen perusahaan harus memiliki strategi khusus untuk membuat produk, mempertahankan produk dan menimbulkan kepuasan pelanggan, yang dengan demikian akan menimbulkan loyalitas tinggi dari konsumen terhadap produk yang di keluarkan oleh perusahaan. Salah satu perusahaan yang mengalami persaingan bisnis adalah Cimory. Cimory memproduksi yoghurt dengan beragam varian rasa, dan yang menjadi pesaingnya adalah Yakult yang sudah lama berada di Indonesia. Penelitian ini akan membahas bagaimana pengaruh brand experience, brand trust, customer satisfaction Cimory terhadap brand loyalty di mata para konsumen.

Keyword : Brand Experience, Brand Trust, Customer Satisfaction, Brand Loyalty, Consumer Goods

\section{PENDAHULUAN}

Kesehatan merupakan hal utama yang harus dijaga oleh masyarakat agar dapat menikmati hidup. Karena tinggi nya minat masyarakat untuk mengkonsumsi makanan dan minuman yang sehat, maka hal inilah yang mendorong banyak perusahaan yang membuat produk susu fermentasi atau yoghurt. Yoghurt di percaya dapat membantu menurunkan tekanan darah tinggi, baik untuk kesehatan kulit, meningkatkan kekebalan tubuh, dan dapat menurunkan berat badan. Berdasarkan hal tersebut, banyak perusahaan yang membuat produk susu fermentasi atau yoghurt yang bukan hanya untuk memasarkan produk saja, akan tetapi untuk memenuhi kebutuhan atau keinginan dari konsumennya, yang terdiri dari berbagai jenis kalangan masyarakat. Salah satu perusahaan yang membuat produk yoghurt dari Indonesia adalah Cimory. Cimory membuat berbagai jenis produk olahan susu dengan berbagai variasi rasa. Cimory harus lebih berinovasi dalam membuat suatu produk yang bisa 
diterima baik oleh masyarakat. Dengan adanya inovasi produk baru yang menghadirkan berbagai variasi rasa yoghurt, diharapkan Cimory mendapat tempat di hati masyarakat Indonesia. Cimory harus berupaya mempertahankan brand experience masyarakat yang telah mencoba produknya, setelah mempertahankan brand experience, Setelah konsumen memiliki brand experience yang baik terhadap Cimory, maka akan terbentuk kepercayaan konsumen pada suatu merek yakni brand trust. Brand trust diartikan sebagai kerelaan konsumen untuk mempercayai kemampuan merek untuk memuaskan kebutuhannya (Kumar, 2008). Cimory harus menanamkan brand trust di masyarakat mengenai produknya. Customer satisfaction juga diperlukan Cimory untuk menyakinkan konsumen bahwa produk Cimory memang pilihan yang tepat untuk dikonsumsi. Setelah brand experience, customer satisfaction, brand trust Cimory harus mempertahankan brand loyalty untuk mempertahankan customer agar selalu membeli produk Cimory karena sudah percaya dan puas dengan produk Cimory. Ketika suatu produk sudah memiliki brand experience, brand trust, dan brand satisfaction yang baik, maka akan membuat konsumen menjadi loyal dengan merek tersebut. Riana (2008) menyimpulkan bahwa trust in brand dapat berpengaruh signifikan terhadap brand loyalty.

\section{TINJAUAN PUSTAKA}

\section{Brand Experience}

Sesuai dengan definisi Brakus, et al. (2009) yaitu konsep pengalaman merek (brand experience) sebagai subjektif, tanggapan konsumen internal (sensasi, perasaan, dan kognisi) dan respon perilaku yang ditimbulkan oleh stimulus yang berhubungan dengan merek yang merupakan bagian dari desain merek dan identitas, kemasan, komunikasi, dan lingkungan.

\section{Brand Trust}

Menurut Kautonen dan Karjaluoto (2008) pada awalnya mendefinisikan brand trust sebagai perasaan aman bahwa suatu merek akan memenuhi harapan konsumen.

\section{Customer Satisfaction}

Menurut Kotler dan Keller (2012) kepuasan adalah perasaan senang atau kecewa dari seseorang yang muncul setalah membandingkan antara persepsi atau kesannya terhadap kinerja (atau hasil) dari suatu produk dan harapan-harapannya. Artinya jika kinerja sesuai dengan apa yang diharapkan oleh konsumen, maka konsumen tersebut akan merasa puas

\section{Brand Loyalty}

Menurut Chi, Yeh, dan Chiou (2009) brand loyalty merupakan tujuan akhir dari manajemen merek dan jika suatu perusahaan ingin menguji kelemahan atau kelebihan dari loyalitas pelanggannya, perusahaan dapat dengan mudah untuk menguji apakah konsumen masih menyukai produk perusahaan tersebut dibandigkan dengan produk pesaing. Chi, Yeh, dan Chiou (2009) mengatakan bahwa perubahan di dalam lingkungan dan strategi pemasaran dapat mempengaruhi perilaku pembelian secara berulang dan akan tetap membeli merek yang sama di masa yang akan datang.

\section{Hipotesis}

Hipotesis merupakan jawaban sementara terhadap rumusan masalah penelitian. Pada penelitian ini, hipotesis yang akan diuji adalah sebagai berikut :

H1 : Brand Experience berpengaruh positif dan signifikan terhadap Brand Loyalty

$\mathrm{H} 2$ : Brand Trust berpengaruh positif dan signifikan terhadap Brand Loyalty 
H3 : Customer Satisfaction berpengaruh positif dan signifikan terhadap Brand Loyalty H4 : Brand Experience, Brand Trust, Customer Satisfaction berpengaruh positif dan

Signifikan terhadap Brand Loyalty

Signifikan terhadap Brand Loyalty

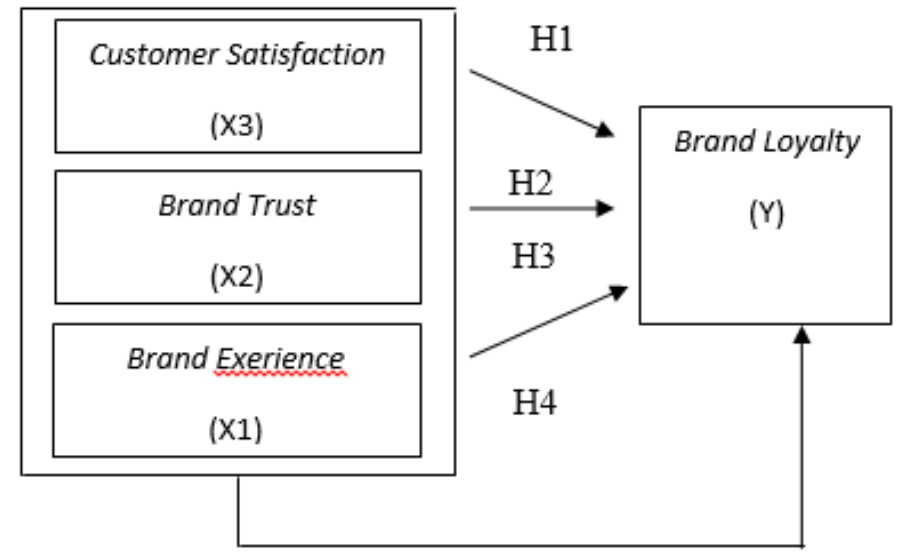

\section{METODOLOGI PENELITIAN}

Metode yang digunakan oleh peneliti adalah metode deskriptif, yaitu Menurut Sugiyono (2007) metode deskriptif adalah metode penelitian yang dilakukan untuk mengetahui nilai variabel mandiri, baik satu variabel atau lebih tanpa membuat perbandingan atau menghubungkan dengan variabel lain.

Persiapan pembuatan kuesioner dilaksanakan pada bulan April - Mei 2018. Jumlah kuesioner yang disebar sebanyak 204 responden. Penulis menyebarkan kuesioner di wilayah Jakarta yang meiliputi : Universitas Tarumanagara, Central Park Mall Jakarta, dan tempat bekerja rekan penulis. Kuesioner dibagikan kepada masyarakat yang sudah pernah mengkonsumsi Yoghurt Cimory

Pengukuran variabel menggunakan skala likert. Menurut Malhotra (2009) skala likert adalah skala yang digunakan secara luas yang meminta responden menandai derajat persetujuan atau ketidaksetujuan terhadap masing-masing dari serangkaian pertanyaan mengenai objek stimulus. Umumnya masing-masing item mempunyai lima kategori yang berkisar antara "sangat setuju" sampai dengan "sangat tidak setuju"

\section{Hasil dan Diskusi}

\section{Hasil}

Dari 204 responden yang menjadi subjek penelitian, data demografik yang di dapatkan adalah sebanyak 55.40\% yang mengkonsumsi Cimory adalah wanita yang berusia di antara 17-25 tahun sebanyak $81.4 \%$. Berdasarkan pekerjaan sebanyak $53.4 \%$ adalah pelajar atau mahasiswa.

Selanjutnya, peneliti melakukan uji asumsi klasik yang terdiri dari uji multikolinearitas, uji heterokedastisitas dan uji normalitas.

\section{Uji Normalitas}

Tampilan output SPSS menunjukkan nilai Asymp Sig 2 tailed untuk brand experience, brand trust, customer satisfaction dan brand loyalty adalah 0.383. Nilai Asymp Sig ini memberikan probabilitas di atas 0.05. Jadi dapat disimpulkan bahwa brand experience, brand trust, customer satisfaction dan brand loyalty mempunyai distribusi normal.

\section{Uji Multikolineritas}


Nilai Tolerance untuk brand experience sebesar 0.493, brand trust sebesar 0.463, dan brand satisfaction sebesar 0.451. Ketiga variabel independen tersebut lebih besar dari 0.1. Dengan demikian tidak terdapat multikolineritas yang berbahaya dalam penelitian ini. Sedangkan nilai VIF dari brand experience sebesar 2.029, brand trust sebesar 2.159, dan brand satisfaction sebesar 2.217. Ketiga variabel independen tersebut lebih kecil cari 10, maka dapat disimpulkan bahwa tidak ada korelasi yang erat antara variabel independen.

\section{Uji Heteroskedastistas}

Nilai sig. 2-tailed untuk brand experience sebesar 0.822, brand trust sebesar 0.480, dan customer satisfaction sebesar 0.886. Ketiga variabel independen terebut lebih besar dari 0.05, dengan demikian tidak terjadi heteroskedastistas dalam penelitian ini.

\section{Analisis Regresi Linier Berganda}

$$
\begin{gathered}
\mathrm{Y}=\mathrm{a}+\mathrm{b} 1 \mathrm{X} 1+\mathrm{b} 2 \mathrm{X} 2+\mathrm{b} 3 \mathrm{X} 3 \\
\text { Brand Loyalty }=-0.169+0.195 \text { Brand Experience }+0.135 \text { Brand Trust }+0.695 \text { Customer } \\
\text { Satisfaction }
\end{gathered}
$$

Nilai -0.169 merupakan nilai konstanta yang menandakan apabila tanpa variabel independen (X1-X3) maka nilai prediksi Y akan menjadi sebsar -0.169. Kemudian ketika ada variabel X1 senilai 0.195 menandakan bahwa apabila nilai X1 mengalami kenaikan satu satuan maka nilai prediksi Y akan meningkat menjadi 0.195. Demikian pula untuk variabel X2 senilai 0.135 menandakan bahwa apabila nilai X2 mengalami kenaikan satu satuan maka nilai prediksi Y akan meningkat menjadi 0.135. Terakhir untuk variabel X3 senilai 0.695 menandakan bahwa apabila nilai X3 mengalami kenaikan satu satuan maka nilai prediksi Y akan meningkat menjadi 0.695 .

\section{Pengujian Hipotesis \\ Uji T}

Berdasarkan hasil penelitian diperoleh nilai untuk yang paling signifikan adalah customer satisfaction dengan nilai $\mathrm{t}=9.646$ dan $\mathrm{p}$ (signifikansi) $=0.000<0.05$ artinya terdapat pengaruh positif dan signifikan dari customer satisfaction terhadap brand loyalty. Oleh sebab itu dapat ditarik kesimpulan bahwa customer satisfaction memiliki pengaruh positif dan signifikan terhadap brand loyalty maka Ho ditolak dan Ha diterima.

Untuk variabel brand experience juga memiliki pengaruh yang signifikan dengan nilai $\mathrm{t}=3.008$ dan $\mathrm{p}$ (signifikansi) $=0.000<0.05$ artinya terdapat pengaruh positif dan signifikan dari brand experience terhadap brand loyalty. Oleh sebab itu dapat ditarik kesimpulan bahwa brand experience memiliki pengaruh positif dan signifikan terhadap brand loyalty maka Ho ditolak dan Ha diterima.

Untuk variabel brand trust juga memiliki pengaruh yang signifikan dengan nilai $\mathrm{t}=$ 2.019 dan $\mathrm{p}$ (signifikansi) $=0.045<0.05$ artinya terdapat pengaruh positif dan signifikan dari brand trust terhadap brand loyalty. Oleh sebab itu dapat ditarik kesimpulan bahwa brand trust memiliki pengaruh positif dan signifikan terhadap brand loyalty maka Ho ditolak dan Ha diterima.

\section{Uji Simultan (Uji F)}

Pada uji menjelaskan bahwa nilai $\mathrm{F}=129.824$ dan $\mathrm{p}$ (signifikansi) $=0.000$ nilai signifikansi $<0.05$ artinya terdapat pengaruh variabel brand experience, brand trust, dan customer satisfaction terhadap brand loyalty secara bersama-sama (simultan).

\section{Koefisien Determinasi}


Pada bagian ini menujukkan perhitungan nilai regresi diperoleh nilai $\mathrm{R}=0.813$, koefisien determinasi $\mathrm{R}^{2}$ ( $\mathrm{R}$ Square) $=0.661$ dimana nilai ini diperoleh dari pengkuadratan dari koefisien korelasi $(0.813$ x 0.813). Hal ini juga menujukkan indeks determinasi yaitu persentase yang menyumbangkan pengaruh $\mathrm{X} 1$, X2, dan $\mathrm{X} 3$ terhadap $\mathrm{Y}$. $\mathrm{R}^{2}=0.661$ mengandung pengertian bahwa $66.1 \%$ sumbangan $\mathrm{X} 1$ - X3 terhadap Y sedangkan sisanya sebesar $34.9 \%$ dipengaruhi faktor lain (100\% - 66.1\%). Selain itu dari bagian ini juga dilihat tidak terjadi problem autokorelasi karena nilai Durbin Watson tidak $<1$ atau $>3$. Jadi besarnya variabilitas dari variabel brand loyalty yang diterangkan dengan menggunakan variabel brand experience, brand trust, dan customer satisfaction adalah sebesar $61.6 \%$, sisanya $38.4 \%$ merupakan faktor yang lainnya.

\section{KESIMPULAN}

Berdasarkan pembahasan dan hasil analisis data pada bab sebelumnya, maka kesimpulan yang dapat ditarik dari penelitian ini adalah :

1. Berdasarkan Uji T, nilai brand experience sebesar 3,008 yakni lebih tinggi dari 0.05. Dari hasil hipotesis pertama dapat di ketahui bahwa brand experience memiliki pengaruh positif dan signifikan terhadap brand loyalty.

2. Berdasarkan Uji T, nilai brand trust sebesar 2,019 yakni lebih tinggi dari 0.05. Dari hasil hipotesis kedua dapat di ketahui bahwa brand trust memiliki pengaruh positif dan signifikan terhadap brand loyalty.

3. Berdasarkan Uji T, nilai customer satisfaction sebesar 9,646 yakni lebih tinggi dari 0.05. Dari hasil hipotesis ketiga dapat di ketahui bahwa customer satisfaction memiliki pengaruh positif dan signifikan terhadap brand loyalty.

4. Berdasarkan Uji F mendapatkan nilai 129,824 yakni lebih tinggi dari 0.05. Dari hasil hipotesis keempat dapat di ketahui bahwa brand experience, brand trust, customer satisfaction memiliki pengaruh positif dan signifikan terhadap brand loyalty.

\section{Saran}

Untuk meningkatkan loyalitas merek, maka saran yang dapat diberikan dan kiranya dapat bermanfaat bagi perusahaan adalah sebagai berikut:

1. Saran Bagi Perusahaan

Saran yang dapat diberikan kepada Perusahaan Yoghurt Cimory adalah untuk menambah varian rasa yoghurt, serta melakukan inovasi sebagai contoh yakni menambahkan potongan buah pada yoghurt. Hal ini dikarenakan nilai rata-rata indikator ini mempunyai nilai rata-rata yang relatif lebih rendah dibandingkan indikator lain (nilai rata-rata untuk indikator "Yoghurt Cimory menstimulasi rasa ingin tahu dan pemecahan masalah saya" sebesar 3.26). Jika Yoghurt Cimory dapat menambah varian rasa dan berinovasi, maka diharapkan banyak konsumen yang tertarik untuk mencoba varian rasa baru dari Yoghurt Cimory.

Perusahaan Yoghurt Cimory harus dapat mempertahankan cita rasa yoghurtnya, hal ini dikarenakan nilai nilai rata-rata indikator ini mempunyai nilai rata-rata yang relatif lebih tinggi dibandingkan indicator lain (nilai rata-rata untuk indicator "Yoghurt Cimory mempunyai varian rasa yang sesuai dengan selera saya" sebesar 4.36).

2. Saran Kepada Akademisi

Penelitian ini hanya meneliti pengaruh variabel brand experience, brand trust, dan customer satisfaction terhadap brand loyalty. Peneliti menyarankan agar penelitian selanjutnya menggunakan variabel brand satisfaction, seperti pada penelitian yang dilakukan oleh Sahin, Zahir dan Kitapci (2011). Limitasi yang lainnya penelitian ini hanya dilakukan di wilayah Jakarta, peneliti menyarankan penelitian selanjutnya dapat melakukan penelitian dengan mencakup wilayah yang lebih luas. 


\section{DAFTAR PUSTAKA}

Azize Sahib, Cemal Zehir, \& Hakan Kitapci. (2011). The Effect of Brand Experience, Trust, and Satisfaction on Building Brand Loyalty; An Empirical Research On Global Brands. Journal of Procedia Sosial and Behavioral Science, 24, 1288-1301.

Brakus J.J., Schmitt B. H.. \& Zarantonello. (2009). Brand Experience: What Is It? How Is It Measure? Does it Affect Loyalty?. Journal of Marketing Vol. 73.

Chi, H.K.,Yeh, H. R., \& Chiou C. Y. (2009). The effect of brand affect on female cosmetic users brand loyalty in Taiwan. The Journal Of American Academy Of Bussiness, 14, 230-236. Kautonen, Teemu \& Heikki Karjaluoto. (2008). Trust and New Technologies: Marketing and Management on The Internet And Mobile Media. Edward Elgar Publishing.

Kotler, Phillip \& Kelvin Lane Keller. (2012). Marketing management. New Jersy: Pearson Education.

Kumar, V. (2008). Managing Customers for Profit. New Jersey : Pearson Education.

Malhotra, Naresh K. (2009). Riset Pemasaran Pendekatan Terapan Jilid 1. Jakarta : PT. Index.

Naga, D.S., (2013). Teori sekor pada pengukuran mental. Jakarta: PT Nagarani Citrayasa.

Riana, Gede. (2008). Pengaruh Trust brand terhadap loyalty brand. Buletin Studi Ekonomi Vol 13.

Sekaran, Uma. (2009). Research Methods for Business. Jakarta : Salemba Empat.

Sugiyono. (2007). Metode Penelitian Pendidikan Pendekatan Kuantitatif, Kualitatif, dan $R \& D$. Bandung: ALFABETA. 
